IGNORE TALENT AT YOUR PERIL

1

\title{
Talent development - Early specialization and critical periods in acquiring expertise: A comparison of Traditional vs. Detection Talent Identification in \\ Team GB Cycling at London 2012
}

(1)

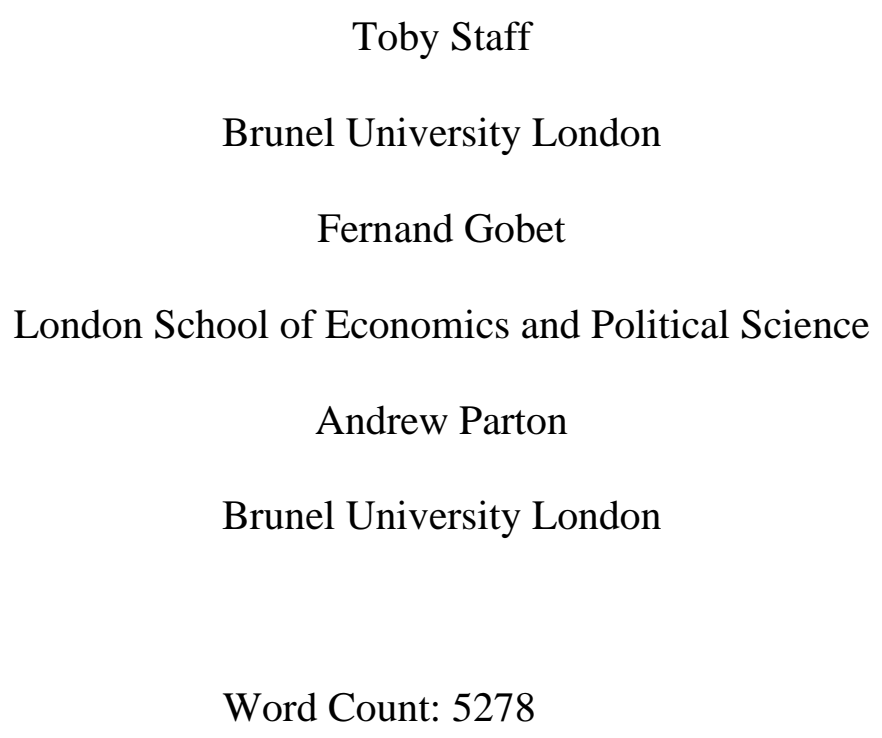

Correspondence concerning this article should be addressed to Toby Staff, Department of Psychology, Brunel University London, Middlesex, UB8 3PH, U.K. Email: Toby.Staff@brunel.ac.uk

\section{Author Note}




\begin{abstract}
The aim of this study was to compare two methodologies employed by the
\end{abstract} British Cycling talent identification programme. Specifically, we investigated cyclists selected to represent GB cycling team at the London 2012 Olympics using (a) a traditional talent identification methodology (British Cycling Olympic Development Programme), where selection is based upon race results and (b) a detection talent identification methodology (UK Sport Talent Team Programme), which is a multiOlympic event initiative that identifies athletic potential from a range of generic, physical and skill-based tests. To facilitate this comparison, we calculated the speed with which expertise was acquired. A Mann-Whitney $U$ test $(U=16.0, p=0.031)$ indicated that the speed of acquiring expertise was quicker in detection talent identification $(M d n .=5.4)$ than traditional talent identification $(M d n .=7.2)$. Practice started later with detection talent identification than with traditional talent identification (14.12 years vs. 11.23 years, respectively), which affected the period to excellence. Thus, detection talent identification resulted in an absence of early specialization, which suggests a critical period for attaining cycling expertise. We hypothesize a genetic basis of talent and propose that a detection talent identification programme provides a better starting point of deliberate practice, traditionally a weakness in calculating the period to excellence.

Keywords: early specialization, critical period, deliberate practice, period to excellence, talent. 
IGNORE TALENT AT YOUR PERIL

61

\section{Introduction}

Talent identification attempts to identify factors that collectively predict an individual's future performance potential, selecting the best candidates for advanced training. Since the late 1990s, British cycling received funding through the UK National Lottery and commercial sponsorship from British Sky Broadcasting Group Plc. Both funding and focused talent identification measures have contributed to a considerable increase in Olympic medal success in cycling for the UK: Sydney 2000 (4 medals), Athens 2004 (4 medals), Beijing 2008 (14 medals), London 2012 (12 medals and Rio 2016 (12 medals). However, there is little available empirical data directly comparing the merits of the different talent identification processes utilized. We focus on two methods used for talent identification in British Cycling, traditional and detection, which afforded the opportunity of directly comparing the outcomes for individuals selected based on either of these two different approaches.

Traditional talent identification methods consist of selecting athletes who are currently involved in their chosen sport (Lidor, Côté, \& Hackfort, 2009) by using achievement measures (e.g., race results, rankings, etc.), expert assessment of performance by coaches and talent scouts within that sport. Thus, motor performance is a key factor in selection and comparative levels of initial motor learning have been achieved through interaction with the task. In sports, the traditional talent identification methodology is the predominant pathway for identifying potential, and $80 \%$ of elite performers were selected using this approach in 12 major sports (English Sports Council, 1998).

An alternate approach is talent identification by detection, which measures components of successful performance (e.g., power, anaerobic capacity, etc.). It is possible to apply this approach to those with no history in the defined sport (Williams \& Reilly, 2000) and those displaying embryonic abilities with little task knowledge. 
This approach thus potentially widens the available pool of performers to any participant willing to attend testing. Furthermore, the generic tests do not require expert facilities and can occur in schools, halls and clubs. Therefore, this provides the potential to identify talented athletes with no prior experience and experienced late developers.

British Cycling talent development pathway, the "Rider Route", utilizes these two talent identification methodologies and provides suitable data that facilitates the comparison of traditional and detection talent identification. The traditional route consists of competitive opportunities resulting in cyclists positioning themselves in the British Cycling Rider Route talent development pathway, which consists of regional and national development centers; placement depends upon maturity and experience. Selection occurs from the age of five (British Cycling, 2020), and competitive results determine progression into the Olympic Development Programme based on race results performance. The detection route is the Talent Team Programme, a multi-Olympic event initiative by UK Sport and coordinated by each governing body (in this case, British Cycling) that identifies athletic potential from a range of generic physical and skill-based tests. Identification occurs by testing candidates between the ages of 11 to 16 years in schools or performance centers. Testing ethics stipulates that the age of 11 years is the earliest testing age (British Cycling, 2020). The selection consists of physiological performance on a Wattbike (turbo trainer), with measures such as power output and peak cadence assessed. Upon selection, cyclists join the Rider Route in preparation for membership of the Great Britain Cycling Team. Apart from age and experience-related differences, the process of motor development for both groups follows a similar path (British Cycling, 2020). The two different selection processes mirror, in part, the theoretical debate in which researchers focus on the importance of practice (Ericsson, Krampe, \& Tesch- 
113 Römer, 1993; Ericsson, Prietula, \& Cokely, 2007; Helsen, Starkes, \& Hodges, 1998;

114 Helsen, Hodges, Van Winckel, \& Starkes, 2000; Law, Côté, \& Ericsson, 2007) or

115 talent (Hambrick, Burgoyne, Macnamara, \& Ullén, 2018; Lombardo \& Deaner, 2014;

116 Staff, Gobet, \& Parton, 2020) in achieving expertise. Those researchers who

117 emphasize the importance of practice largely deemphasize the role of talent. Ericsson

118 et al. (1993) stated that, for children, early practice is significant and must coincide

119 with biological and cognitive development. Furthermore, early specialization is

120 relevant in children, as later starters would not be able to "catch up" (Ericsson et al.,

121 2007). However, there is still a considerable debate as to the impact of early practice

122 to expertise (Baker, Joseph, Cobley, \& Fraser-Thomas, 2009; Crisp, 2019; DiFiori et

123 al., 2017; Yustres et al., 2019) and negative outcomes have been reported, including

124 its potential to reduce overall motor skill development (Myer et al., 2016) and its

125 influence in facilitating burnout and injury (Malina, 2010).

By contrast, researchers who argue for a contribution from innate talent in

127 acquiring expertise highlight the importance of critical periods (Chassy \& Gobet,

128 2010; Tucker \& Collins, 2012), which are hypothesized to rely upon genetic

129 programming (Viru et al., 1999). Such talents result in accelerating expertise

130 (Lombardo \& Deaner, 2014) and providing an opportunity for early diversification

131 (Staff et al., 2020) that can lead to a growth in motor development (Myer et al., 2016).

132 Researchers investigating elite performers have focused on developmental

133 history and talent identification programmes for an explanation of individual

134 differences (Ford \& Williams, 2012; Güllich \& Emrich, 2014; Güllich, 2014; Güllich,

135 2017), although direct comparisons between elite performers having followed these

136 two routes have been infrequent (Barth, Emrich, \& Güllich, 2019). To compare both

137 selection methods, we utilized methodologies developed to assess the Deliberate

138 Practice hypothesis (Ericsson et al., 1993) and in particular applied its definition of 
139 the start of practice and the attainment of expertise. This enabled us to calculate a

140 chronological measure for expert achievement. We termed this the "period to

141 excellence", which consisted of practice and recovery periods associated with

142 developmental expertise (Bompa \& Carrera, 2005; Gibala, MacDougall, Tarnopolsky,

143 Stauber, \& Elorriaga, 1995). These recovery periods are important in reducing

144 overtraining and injury as well as allowing other life activities (Grandou, Wallace,

145 Impellizzeri, Allen, \& Coutts, 2020) and do not include practice that mitigate burnout

146 (Lopes \& Vallerand, 2020).

147 To quantify the effectiveness of these talent identification methods in selecting

148 potential elite performers, we compared how quickly cyclists acquired expertise (elite

149 proficiency), operationalized as their period to excellence. We anticipated that a

150 natural talent selection process, which focused on the specific task demands, would

151 lend itself to the quicker acquisition of expertise. Our hypothesis is that those

152 individuals selected by detection talent identification would develop faster than those

153 selected using traditional talent identification.

Method

\section{Participants}

The study includes data on all 27 cyclists (12 women and 15 men) selected for

157 Team GB in the London 2012 Olympics. Cyclists were aged 17 to 34 years (Men: $M$

$158=20.36, S D=1.23$; Women: $M=21.23, S D=4.62)$ when they achieved expertise.

159 The starting point of deliberate practice ranged from 5.00 to 27.02 years of age. The

160 cyclists were divided into two talent identification groups: detection talent

161 identification $(n=9)$ and traditional talent identification $(n=18)$. A comparison of

162 medals awarded shows that athletes selected by detection talent identification gained

163 three individual medals and five team medals and that athletes selected by traditional

164 talent identification gained five individual medals and five team medals. 


\section{Data Collection}

We identified all Team GB cyclists selected for the London 2012 Olympics and collected their date of birth as well as the starting and finishing points of deliberate practice. The following sources were used. First, the British Cycling (n.d.) website contained riders' biographies and provided many basic data points such as age and cycling history. Second, public domain biographical information was obtained from Internet sources, local newspaper reports, cycling magazines and social media, with particular focus on the cyclists' initiation of deliberate practice. Finally, the British cycling website provided a list of athletes' agents and representatives, who were contacted with the following questions regarding the athlete they represented: (a) When did you start to focus on your sport? (b) At what age were you first coached for your sport? and (c) Did you train at any other sport prior to you focusing on your main sport? If yes, which sport(s)?

\section{Measures}

We utilized the parameters used by the deliberate practice framework (Ericsson et al., 1993) to calculate cyclists' period to excellence, which was defined as the difference between the starting point of formal training (defined as joining a club and/or obtaining regular coaching) and the first selection in a senior international competition (either the Commonwealth games, European championships, World Cup or the Olympic games).

To estimate when cyclists first joined the British cycling talent identification programme, we used the publicly available information on the British cycling website and/or athletes' personal websites. Cyclists' talent identification selections were divided into traditional and detection. Traditional talent identification cyclists were selected based on competitive results and were placed in the Riders Route at a stage that was consummate with their performance and experience. Detection talent 
193 identification cyclists were selected based on threshold measures, usually through

194 testing days in the school environment; these athletes had no formal competitive

195 experience. Upon selection, they entered the Olympic talent team programme, the

196 initial stage of the Riders Route.

\section{Results}

198

199

200

201

202

204

205

206

207

208

209

Table 1. Period to excellence for traditional and detection methods

\begin{tabular}{ccccrr}
\hline \multicolumn{1}{l}{$\begin{array}{l}\text { Talent identification } \\
\text { method }\end{array}$} & $\mathrm{N}$ & Mean & SD & Minimum & Maximum \\
\hline Traditional & 18 & 9.94 & 5.55 & 5.00 & 27.02 \\
\hline Detection & 9 & 5.79 & 2.32 & 3.24 & 9.86 \\
\hline
\end{tabular}

Table 2. Starting age for traditional and detection methods

\begin{tabular}{ccccrr}
\hline $\begin{array}{l}\text { Talent identification } \\
\text { method }\end{array}$ & $\mathrm{N}$ & Mean & SD & Minimum & Maximum \\
\hline Traditional & 18 & 11.23 & 5.55 & 5.00 & 27.02 \\
\hline Detection & 9 & 14.12 & 1.45 & 11.01 & 16.01 \\
\hline
\end{tabular}

Table 3. Expertise age for traditional and detection methods

\begin{tabular}{ccccrr}
\hline $\begin{array}{l}\text { Talent identification } \\
\text { method }\end{array}$ & $\mathrm{N}$ & Mean & SD & Minimum & Maximum \\
\hline Traditional & 18 & 21.17 & 3.75 & 16.71 & 33.70 \\
\hline Detection & 9 & 19.91 & 1.24 & 18.25 & 22.87 \\
\hline
\end{tabular}

\section{Period to Excellence as a function of Starting Age}

215 excellence as criterion variable. The regression equation was: period to excellence $=$ 
$21615.250-(.549 \times$ starting age $) ; p<.001 ;$ adjusted $r^{2}=.541$. Thus, each additional

217 starting year reduced period of excellent by about half a year. After removing two

218 athletes who started after 20 years of age (20 years and 27 years, respectively), the

219 equation becomes: period to excellence $=19.250-(.937 \times$ starting age $) ; p<.001$;

220 adjusted $r^{2}=.821$. The later start resulted in faster expertise and each additional

221 starting year now reduces period of excellent by nearly one entire year. Inserting the

222 relevant mean starting age (respectively, 11.23 years and 14.12 years) in the

223 regression equation yields a predicted period to excellence of 8.73 years for

224 traditional talent identification and 6.02 years for detection talent identification.

\section{Starting and Expertise Age as a function of talent identification pathway}

Shapiro-Wilk test of normality indicated that the data violated the assumptions of normality: Period to excellence, $\mathrm{W}=0.926, p=0.054$; Start Age, $W=0.854, p<$ compare the starting age and expertise age for detection $(n=9)$ and traditional talent significant difference for starting age $(U=37.0, p=0.025)$ between detection talent identification $(M d n .=14.01)$ and traditional talent identification $(M d n .=10.51)$ but there was no statistically significant difference with respect to expertise age ( $p=$ 0.348).

\section{Period to Excellence as a function of talent identification pathway}

We hypothesized that the speed of expertise achieved in British Cycling talent

240 identification was quicker with detection when compared with traditional methods. To 241 attain an equitable comparison of the different talent identification methodologies, we 242 removed all data from the traditional talent identification group with a starting age of 
243 less than eleven, which is the minimum age that athletes enter the training programme

244 based on talent identification. A Mann-Whitney U test indicated that the period to

245 excellence was quicker in detection talent identification $(M d n .=5.4, n=9)$ than

246 traditional talent identification $(M d n .=7.2, n=9), U=16.0, p=0.031$.

247 All nine cyclists (100\%) selected using detection talent identification and ten

248 traditional talent identification cyclists (56\%) reached elite level in under 10-years. A

249 single sample t-test was conducted to determine if there was a statistically significant

250 overall difference between the observed period to excellence and the ten-year period

251 of deliberate practice predicted by Ericsson et al. (1993). The period to excellence

252 for the entire sample $(M=8.55$ years, $S D=3.50$ years $)$ was statistically significantly

253 lower than 10 years, $t(26)=-2.15, p=.041$.

\section{Discussion}

255 This paper tested the hypothesis that the time required to become an expert

256 cyclist varies depending on the type of talent identification methodology (traditional

257 or detection) used for the initial selection. We used data from the cyclists

258 representing Team GB in Cycling at London 2012 Olympics selected by the British

259 Cycling talent identification programme. We predicted that those cyclists selected by

260 the detection talent identification route would develop to expertise quicker (shorter

261 period to excellence) than those chosen using the traditional talent identification route.

262 The results show that the median period to excellence of British Cyclists

263 representing Team GB at London 2012 was significantly quicker when selection was

264 made by detection talent identification $(M d n .=5.4 \mathrm{yrs}$.$) than traditional talent$

265 identification $(M d n .=7.2$ yrs. $)$. This result indicates that the introduction of detection

266 measures in the Talent Team Programme by UK Sport has resulted in Cyclists

267 acquiring elite expertise faster than traditional talent identification methods. We

268 therefore postulate that faster motor learning and development may be a consequence 
269 of attendant talent and an interaction with starting age, individual differences and

270 talent identification methodology. This result is inconsistent with previous claims that

271 the journey to expertise is 10 years (Ericsson et al., 1993) and concurs with previous

272 sport research such as sprinting plus track and field (Lombardo \& Deaner, 2014; Staff

273 et al., 2020) indicating that the average mean period to excellence was less than 10

274 years, which suggests that talent contributes to performance.

275

276

277

278

\section{Starting Age}

When comparing talent identification methodologies in cycling using the period to excellence measures, the difference between detection talent identification $(\mathrm{M}=5.79$ yrs., $\mathrm{n}=9)$ and traditional talent identification $(\mathrm{M}=9.94$ yrs., $\mathrm{n}=18)$ resulted in a 4.15-years acceleration of expertise. The 4.15-years acceleration in the speed of expertise for detection talent identification is calculated by a later starting age and the faster motor development period. The later starting age accounted for 2.89 years $=(14.12-11.23)($ see Table 2$)$. These results question the necessity of early practice in acquiring expertise, which for becoming an Olympic medalist has been claimed to be significant (Ericsson et al., 1993; Ericsson et al., 2007).

A Mann Whitney U test also indicated a significant difference between start age for detection $(M d n .=14.01 \mathrm{yrs}$.$) and traditional (M d n .=10.51 \mathrm{yrs}$.$) talent$ identification. The ethics that guide the minimum physiological testing age in children led us to anticipate a considerable contribution from the starting age in the overall acceleration of expertise. This research identifies eleven years as the earliest testing age for detection talent identification in British Cycling but accepts children as young as five into their traditional talent identification program (British Cycling, 2020). The six-year difference between these two talent identification methods potentially results in detection cyclists having a greater diversification on skills which can have a positive effect of skill acquisition (Güllich, 2014; Güllich, 2017; Staff et al., 2020; 
296 Vaeyens, Güllich, Warr, \& Philippaerts, 2009). Conversely, traditional cyclists have

297 specialized in their sport from an early age. Our results indicate that this was not

298 advantageous, which agrees with research across multiple sports (Baker et al., 2009;

299 Crisp, 2019; DiFiori et al., 2017; Yustres et al., 2019).

300 A comparison of cyclists from both talent identification methods with similar

301 starting dates indicated a significant difference between the period to excellence in

302 detection talent identification $(M d n .=5.4)$ when compared with traditional talent

303 identification $(M d n .=7.2)$. Thus, a later engagement in the development of expertise

304 resulted in faster skill acquisition, which supports the idea of critical periods in which

305 individuals are likely to make an above normal response to exercise (Armstrong,

306 Williams, Balding, Gentle, \& Kirby, 1991; Baxter-Jones, 1995; Malina, 1994; Malina,

307 Eisenmann, Cumming, Ribeiro, \& Aroso, 2004). This concept is hypothesized to be

308 reliant upon genetic programming (Viru et al., 1999) and suggests that developmental

309 factors should align with task demands to facilitate skill acquisition (Armstrong,

310 Williams, Balding, Gentle, \& Kirby, 1991; Baxter-Jones, 1995; Malina, 1994; Malina,

311 Eisenmann, Cumming, Ribeiro, \& Aroso, 2004). This research suggests that the

312 critical period for cycling detection talent identification is 11 to 16 years.

313 Therefore, we believe that a later starting age will be a consistent feature of

314 research using physiological measures and that critical periods should be a feature of

315 talent identification processes throughout sports. For example, a critical period of six

316 years (11 to 16 years) for detection results in a more focused approach to talent

317 identification when compared with the broad range of 22 years (5 to 27 years) of

318 traditional talent identification, considerably narrowing the target field for selection.

319 Expert Age

Those participants selected by detection talent identification resulted in

322 acquiring expertise 1.26 years (i.e., 21.17 - 19.91) quicker (see Table 3). Our results 
323 indicated that the period to excellence was significantly quicker for the detection

324 cyclists. Therefore, the concept of critical periods (Viru et al., 1999) leads us to

325 speculate that the synergy between talent and developmental factors which facilitated

326 the later starting date and the specialized training also brought about enhanced

327 opportunities for the further development of expertise (Svetlov, 1972). Although this

328 research indicates acceleration in expertise, this does not necessarily occur at a

329 uniform rate across the acquisition period (Scott, 1986).

\section{Genetics and Individual Differences}

British cycling utilizes measures of power output and anaerobic capacity

334 within detection talent identification, considering these factors important for cyclists

335 progressing faster in sport. An often-cited definition of talent states that it has "its

336 origin in genetically transmitted structures" (Howe, Davidson, \& Sloboda, 1998, p.

337 406). Some researchers state that "the potential impact of genetics could be great, and

338 thus further research in this area is warranted, in particular in relation to specific

339 performance genes, training/learning genes and genes underpinning injury proneness"

340 (Rees et al., 2016, p. 1044). Associations between component abilities and

341 performance have been identified by genetics research, which has shown that a

342 positive genetic profiling benefits performance. The ACE gene (Angiotensin-

343 converting enzyme) has been associated with positive cardiovascular system and

344 skeletal muscle adaptations (Montgomery et al., 1998; Yang et al., 2003). The

345 ACTN3 gene (Alpha-actinin skeletal muscle isoform 3) has been found to be

346 beneficial in elite power and sprint athletes (Chan et al., 2008; Yang et al., 2003) and

347 the CKM gene (Creatine Kinase Muscle) has been associated with the response to

348 training of $\mathrm{VO}_{2} \max$ (Pennington Biomedical Research Centre, 2013). Although the

349 current research suggests that detection talent identification leads to acceleration in 
350

351

352

353

acquiring expertise, it does not suggest that it is talent alone that determines the period to expertise. Research that specifically identifies the genetic determinants of expert performance is still very much in its infancy (see Ahmetov \& Fedotovskaya, (2012) . In addition, it is likely that expert performance will be a result of a combination of genes rather than a single gene variant.

Indeed, the explanation of critical periods in acquiring motor expertise relies upon genetic programming for the appearance of new events such as growth, maturation and development (Viru et al., 1999). We speculate that innate individual differences can lead to variability in the period to excellence. Our results indicate the implementation of the Talent Team Programme by UK Sport as applied to British Cycling affects the speed of motor learning and development, we suggest it is utilized across multiple sports (see also https://www.uksport.gov.uk/our-work/talent-

id/previous-campaigns).

\section{Selection of talent identification measures}

Traditional talent identification occurs by choosing high performing children with the expectation that their motor learning and development will lead to the same comparative expertise as adults. As sports developed, talent identification practitioners evolved their approach. Coaches deconstructed expertise into information processing components (Schneider \& Shiffrin, 1977; Shiffrin \& Schneider, 1977), reassembling into the complete performance (Griffin, n.d.; Lydiard \& Gilmour, 2000). Tests involving subcomponents of cycling are identified as significant contributors to performance (Paton \& Hopkins, 2001; Wattbike, 2010). However, it is likely that contributions from other factors such as anthropometric measures (Foley, Bird, \& White, 1989) and genes not associated with these measures, (Davids \& Baker, 2007) influence these results. 
cyclists at the sampling period of 11 to 16 years of age, offering the opportunity to all

\section{within that age group to try-out. Selection by the appropriate genetic profile provides}

\section{the opportunity for selection from other sports with a genetic profile akin to cycling.}

The qualitative analyses of the two track endurance gold medalists selected by these measures agree with this suggestion; both had keen interests in athletics and swimming before being tested in cycling. These results conflict with the idea that expertise is associated solely with practice (Ericsson et al., 1993) and agree with the hypothesis that innate ability contributes to expertise (Hambrick et al., 2018). Indeed, innate ability can accelerate expertise and is identifiable by specific talent identification methods.

It seems you might also consider how the different talent ID method may broaden the net at different sampling periods such that it identifies people with the appropriate genetic profile and potential for cycling but who for whatever reason may have been interested in a different sport and/or just did not realize that cycling fit their body type, etc.

\section{Period to Excellence}

Theorists who do not subscribe to a single factor hypothesis to explain expertise - the practice vs. talent dichotomy - endorse a multi-component explanation to expertise (Ackerman, 2014; Gobet, 2015). We suggest that our measure of the period to excellence offers a more holistic approach to identifying the time applied to acquiring expertise, as this not only includes practice but also recovery periods, which allows for physiological adaptations. Therefore, given the same level of expertise, it would be expected that times for the period to excellence would exceed deliberate practice. 
There are pitfalls in determining the starting point of deliberate practice and

404 correspondingly our measures, which we utilized to ascertain our period to excellence

405 measure. This is highlighted in our data by the responses from the most decorated GB

406 Olympic cyclist to the following questions:

$407 \quad$ When did you start to focus on your sport?

$408 \quad$ Response: 17.

$409 \quad$ At what age were you first coached for your sport?

$410 \quad$ Response: 24.

411 Ericsson et al. (1993) suggest that the starting point can be identified by either

412 of these questions; yet the 7-year variation in this response highlights the difficulty in

413 obtaining the actual starting point of deliberate practice. As a result, we took the most

414 cautious approach by using the date the athlete first focused on their sport.

416 international competition. Some athletes make the transition from junior to senior

417 competition seamlessly and therefore the junior achievement date would seem to be

418 applicable. We consider that, due to the importance of physiological capabilities in the

419 cycling task, it would be prudent to choose the senior, or later attainment measure.

There are also operational differences between the calculation of the deliberate

421 practice period (Ericsson et al., 1993) and period to excellence. This is largely brought

422 about by the different domains of research, e.g., violinists and cyclists. Deliberate

423 practice is defined as effortful activities designed to optimize improvement; it can be

424 intermittent and is a measure of practice activities only. Our measure, the period to

425 excellence takes into account practice, injury and physiological adaptation that require

426 rest (Rivera-Brown \& Frontera, 2012). Ericsson recently added to the deliberate

427 practice hypothesis by stating that "the most important point is that high-intensity

428 physical activity can only be maintained for a short period and thus its effectiveness 
429 for stimulating change and improvement of performance cannot be measured by its

430 duration" (Ericsson, 2020, p. 170). Conversely, we contend that bringing about

431 positive improvements in motor development are important and that high intensity

432 physical activity in combination with rest contributes to expertise in cycling; for

433 examples isometrics (Kordi et al., 2020), weight training (Tiberiu et al., 2020) and

434 oxygen uptake (Paton \& Hopkins, 2001) and should not be dismissed.

435 In order to attain cycling expertise, research suggests that maximal and

436 submaximal physiological performance need to be achieved (Mujika \& Padilla, 2001).

437 To realize these physiological milestones, it is possible to apply a "power law"

438 (Newell \& Rosenbloom, 1981), equating the amount of time in acquiring expertise

439 (the period to excellence) with physiological performance. Thus, the greater time

440 applied equated to larger physiological gains. Indeed, cycling research indicates that

441 the levels of aerobic fitness and off-road cycling performance were significantly

442 associated (Impellizzeri, Rampinini, Sassi, Mognoni, \& Marcora, 2005).

443 Deliberate practice

444

Although it may not seem immediately clear as to why research into music

446 expertise should be used in sport, it is evident from the popularity of the deliberate

447 practice framework in sports research that many researchers have taken the intention

448 of Ericsson et al.'s (1993) paper to refer to expertise in general. Furthermore, in that

449 paper the section in the literature review "Distinct Physical Characteristics of Elite

450 Performers" (Ericsson et al., 1993, p. 394) largely focuses on the physiological

451 adaptation that become apparent as sport expertise is attained - heart, lungs, bones

452 and muscles including the quantity of fast and slow twitch fibres. Therefore, it is not

453 surprising that it has consistently been applied to sport (for examples see, Baker, J.,

454 Côté, \& Deakin, 2005; Helsen et al., 1998; Helsen et al., 2000; Hodges, Kerr, Starkes, 
455

456

458

459

460

\& Weir, 2004; Lombardo \& Deaner, 2014; Ward, P., Hodges, N.J., Williams, A.M. \& Starkes, J., 2007).

The deliberate practice hypothesis largely claims that talent (except height and weight in some sports, and the ability to engage in long durations of deliberate practice) does not contribute to the speed of acquiring expertise and that a minimum of 10 years of motivated practice is required to acquire expertise (Ericsson et al., 1993). The current research suggests a different hypothesis: it takes less than 10 years to achieve expertise, with disparities being a function of individual differences, in part related to talent (Lombardo \& Deaner, 2014; Staff et al., 2020) but also associated with sport selection (Baker et al., 2005; Helsen et al., 1998).

\section{Medalists}

At the London Olympics, twenty-seven GB cyclists were selected across events that included track sprint and endurance, time trials, road race, BMX and mountain bike. The details of the medals awarded are listed in table 4. Eighteen were selected from the traditional group, of whom seven won medals consisting of eight gold and two bronze medals in of track and time trials only. British Cycling did not win a medal on either the road race, BMX or mountain biking.

Table 4. Talent identification and its contribution to the Cycling medal total at London 2012 Olympics.

$$
\text { Quantity of Events Medal (Gold-Silver-Bronze) }
$$

\begin{tabular}{ccccc}
\hline Event & Traditional & Detection & Traditional & Detection \\
\hline Track Sprint & 3 & 5 & $2-0-0$ & $4-1-0$ \\
\hline Track Endurance & 7 & 4 & $5-0-1$ & $3-0-0$ \\
\hline Road Time Trial & 3 & 1 & $1-0-1$ & $0-0-0$ \\
\hline Road Race & 4 & 1 & $0-0-0$ & $0-1-0$ \\
\hline BMX & 2 & 0 & $0-0-0$ & $0-0-0$
\end{tabular}




\begin{tabular}{ccccc}
\hline Mountain & 2 & 0 & $0-0-0$ & $0-0-0$ \\
\hline Total & 21 & 11 & $8-0-2$ & $7-2-0$
\end{tabular}

476

477

478

479

480

481

482

483

484

485

486

487

488

489

490

491

492

493

494

495

496

497

498

499

At the 2012 London Olympics traditional talent identification follows the historical convention of selection since the first Modern Olympic Games in 1896, approximately 116 years ago. Conversely, we estimate detection identification has been taking place for at only about 12 years. The medal haul for talent identification method in London was yielded ten medals for traditional talent identification and nine detection talent identification. Thus, it would seem detection talent identification has a future in selecting our next Cycling Olympians.

\section{Limitations}

Our sample size was relatively small, which might result in skepticism with respect to the generalization of the results into other fields. However, it should be noted that it is normally accepted that sample size is context-dependent (Lenth, 2001) and our statistical tests were suited to small populations (Field, 2009). While not perfect, our methodology is recommended in hard-to-reach populations such as elite athletes (Staff et al., 2020). We attempted to mitigate this by using online data 
500 collection methods, which are considered at least as good as in-person data (Casler,

501 Bickel, \& Hackett, 2013; Gosling, Gaddis, \& Vazire, 2007; Vazire \& Gosling, 2004). The current research provides an important comparison between talent identification methodologies within British Cycling. We are somewhat surprised that such comparisons are not published or are not the norm in performance overviews and the assessment of resource efficiency. Is there an expectation that detection will produce expertise and the comparison with traditional methods is unproductive? Researchers have suggested that talent identification consists of highly rationalized myths rather than highly efficient norms (Barth et al., 2019); we suggest that the lack of such research is a good example of this attitude.

\section{Summary and Conclusions}

511

512
What are the implications for resources utilized in developing methods that contribute to the acceleration of expertise? The objective of talent identification is to assess athletes, identify potential for senior elite performance and recruit them into sport-specific programmes. Once athletes are selected, the financial imperative is to ensure that all practical means are used to accelerate the acquisition of expertise. This involves optimizing coaching, competitive opportunities, medical and scientific interventions (Vaeyens, Güllich, Warr, \& Philippaerts, 2009). The detection methodology has a number of benefits for talent identification: (a) increasing the pool of athletes suitable for potential Olympic selection, potentially leading to greater competition for places and higher performance standards; (b) increasing the efficiency in the allocation of resources brought about by faster skill acquisition; (c) providing information on associations between genetic factors and likely performance outcomes; and (d) introducing a wider range of potential participants to Olympic sports. UK Sport has utilized this methodology across other Olympic sports 
527 (https://www.uksport.gov.uk/our-work/talent-id). Further research would be required

528 to determine if these results could be generalized across all sporting domains.

529 This research has shown that the speed of acquiring elite performance utilizing

530 detection talent identification was superior when compared to traditional talent

531 identification and proposes a methodology that associates individual differences with

532 the speed of acquiring expertise. These results indicate that detection talent

533 identification is a quicker route to develop expertise and supports the introduction of

534 the Talent Team Programme introduced by UK Sport as a precursor to individual

535 Olympic Sports talent identification programmes. It questions the assumption that

536 early learning is necessary for acquiring expertise and supports the hypothesis that

537 both critical periods and therefore genetic factors align with tasks, contributing to

538 accelerating the acquisition of expertise in sports. Innate talent is a rare commodity in

539 motor learning and development, and to ignore athletes' genetic potential in talent

540 identification is not rational. It is hoped this paper will promote debate into a more

541 rounded understanding of factors that contribute to the acceleration of expertise.

542
References

Ackerman, P. L. (2014). Nonsense, common sense, and science of expert performance: Talent and individual differences. Intelligence, 45, 6-17. doi:10.1016/j.intell.2013.04.009

Armstrong, N., Williams, J., Balding, J., Gentle, P., \& Kirby, B. (1991). The peak oxygen uptake of British children with reference to age, sex and sexual 
550

551

552

553

554

555

556

557

558

559

560

561

562

563

564

565

566

567

568

569

570

maturity. European Journal of Applied Physiology and Occupational Physiology, 62(5), 369-375.

Baker, J., Côté, J., \& Deakin, J. (2005). Expertise in ultra-endurance triathletes early sport involvement, training structure, and the theory of deliberate practice. Journal of Applied Sport Psychology, 17(1), 64-78.

Baker, J., Cobley, S., \& Fraser-Thomas, J. (2009). What do we know about early sport specialization? Not much! High Ability Studies, 20(1), 77-89.

Barth, M., Emrich, E., \& Güllich, A. (2019). A machine learning approach to "revisit" specialization and sampling in institutionalized practice. SAGE Open, 9(2), 2158244019840554.

Baxter-Jones, A. D. (1995). Growth and development of young athletes. should competition levels be age related? Sports Medicine, 20(2), 59.

Bompa, T. O., \& Carrera, M. (2005). Periodization training for sports (2nd ed.). Leeds: Human Kinetics.

British Cycling. (2020). British cycling handbook 2020 (2020th ed.)

British Cycling. (n.d.). Rider biographies. Retrieved 07/09, 2013, from http://www.britishcycling.org.uk/gbcyclingteam/article/Gbrst GreatBritain-Cycling-Team-Olympic-Programmes

Casler, K., Bickel, L., \& Hackett, E. (2013). Separate but equal? A comparison of participants and data gathered via amazon's MTurk, social media, and faceto-face behavioral testing. Computers in Human Behavior, 29(6), 2156. 
571 Chassy, P., \& Gobet, F. (2010). Speed of expertise acquisition depends upon

572 inherited factors. Talent Development and Excellence, 2(1), 17-27.

573 Crisp, P. (2019). Sidestepping talent ID models: Avoiding early specialisation,

574 maintaining participation, and focusing on the participant as an athlete.

575 Journal of Sport and Games, 1(4), 16-21.

576 Davids, K., \& Baker, J. (2007). Genes, environment and sport performance: Why the 577 nature-nurture dualism is no longer relevant. New Zealand: Adis

$578 \quad$ International.

579 DiFiori, J. P., Brenner, J. S., Comstock, D., Côté, J., Güllich, A., Hainline, B., et al.

580 (2017). Debunking early single sport specialisation and reshaping the youth 581 sport experience: An NBA perspective. British Journal of Sports Medicine,

582 English Sports Council. (1998). The development of sporting talent 1997: An

583 examination of the current practices for talent development in English sport,

$584 \quad$ English Sports Council.

585 Ericsson, K. A. (2020). Towards a science of the acquisition of expert

586 performance in sports: Clarifying the differences between deliberate

$587 \quad$ practice and other types of practice. Journal of Sports Sciences, 38(2), 159$588 \quad 176$.

589 Ericsson, K. A., Krampe, R. T., \& Tesch- Römer. (1993). The role of deliberate 590 practice in the acquisition of expert performance. Psychological Review, 100, $591 \quad 363-406$. 
592 Ericsson, K. A., Prietula, M. J., \& Cokely, E. T. (2007). The making of an expert.

$593 \quad$ United States.: Harvard Business School Press.

594 Field, A. P. (2009). Discovering statistics using SPSS: And sex and drugs and rock ' $n$ ' 595 roll. London: SAGE.

596 Foley, J. P., Bird, S. R., \& White, J. A. (1989). Anthropometric comparison of 597 cyclists from different events. British Journal of Sports Medicine, 23(1), 3059833.

599

600

601

602

603

604

605

606

607

608

609

610

611

613

Ford, P. R., \& Williams, A. M. (2012). The developmental activities engaged in by elite youth soccer players who progressed to professional status compared to those who did not. Psychology of Sport and Exercise, 13, 349-352.

Gibala, M. J., MacDougall, J. D., Tarnopolsky, M. A., Stauber, W. T., \& Elorriaga, A. (1995). Changes in human skeletal muscle ultrastructure and force production after acute resistance exercise. Journal of Applied Physiology, $78(2), 702-708$.

Gobet, F. (2015). Understanding expertise: A multidisciplinary approach. . London: Palgrave.

Gosling, S. D., Gaddis, S., \& Vazire, S. (2007). Personality impressions based on facebook profiles. International Conference on Weblogs and Social Media, Boulder, Colorado, USA.

Grandou, C., Wallace, L., Impellizzeri, F. M., Allen, N. G., \& Coutts, A. J. (2020).

612 Overtraining in resistance exercise: An exploratory systematic review and methodological appraisal of the literature. Sports Medicine, 50(4), 815-828. 
614 Griffin, G. :. (n.d.). Core skills for

615 hockey.http://www.whitfordhockey.asn.au/cms/wp-

616 content/uploads/2012/02/hockey-core-skills.pdf

617 Güllich, A. (2014). Many roads lead to Rome - developmental paths to Olympic

618 gold in men's field hockey. European Journal of Sport Science, 14(8), 763-771.

619 Güllich, A. (2017). International medallists' and non-medallists' developmental

620 sport activities - a matched-pairs analysis. Journal of Sports Sciences, 35(23),

$621 \quad 2281-2288$.

622 Güllich, A., \& Emrich, E. (2014). Considering long-term sustainability in the 623 development of world class success. European Journal of Sport Science, 14 $624 \quad$ Suppl 1(sup1), S383-S397.

625 Hambrick, D. Z., Burgoyne, A. P., Macnamara, B. N., \& Ullén, F. (2018). Toward a 626 multifactorial model of expertise: Beyond born versus made. Annals of the 627 New York Academy of Sciences, 1423(1), 284-295.

628 Helsen, W. F., Hodges, N. J., Van Winckel, J., \& Starkes, J. L. (2000). The roles of 629 talent, physical precocity and practice in the development of soccer $630 \quad$ expertise. Journal of Sports Sciences, 18(9), 727-736.

631 Helsen, W. F., Starkes, J. L., \& Hodges, N. J. (1998). Team sports and the theory of 632 deliberate practice. Journal of Sport and Exercise Psychology., 20(1), 12-34.

633 Hodges, N. J., Kerr, T., Starkes, J. L., \& Weir, P. L. \&. N., A. (2004). Predicting 634 performance times from deliberate practice hours for triathletes and 
swimmers: What, when and where is practice important. Journal of Experimental Psychology: Applied., 10(4), 219-237.

637

638

Lydiard, A., \& Gilmour, G. (2000). Running with Lydiard Meyer \& Meyer Verlag.

Impellizzeri, F. M., Rampinini, E., Sassi, A., Mognoni, P., \& Marcora, S. (2005). Physiological correlates to off-road cycling performance. Journal of Sports Sciences, 23(1), 41-47.

Kordi, A. M., Folland, J., Goodall, S., Menzies, C., Patel, T. S., Evans, M., et al. (2020). Cycling-specific isometric resistance training improves peak power output in elite sprint cyclists. Scandinavian Journal of Medicine \& Science in Sports,

Law, M., Côté, J., \& Ericsson, K. A. (2007). Characteristics of expert development in rhythmic gymnastics: A retrospective study. International Journal of Sport Psychology, 5, 82-103.

Lenth, R. V. (2001). Some practical guidelines for effective sample size determination. The American Statistician, 55(3), 187-193.

Lombardo, M. P., \& Deaner, R. O. (2014). You can't teach speed: Sprinters falsify the deliberate practice model of expertise. PeerJ, 2, e445.

Lopes, M., \& Vallerand, R. J. (2020). The role of passion, need satisfaction, and conflict in athletes' perceptions of burnout. Psychology of Sport and Exercise, , 101674. athletes. Exercise and Sport Sciences Reviews, 22, 389. 
656 Malina, R. M. (2010). Early sport specialization: Roots, effectiveness, risks.

657 Current Sports Medicine Reports, 9(6), 364-371.

658 Malina, R. M., Eisenmann, J. C., Cumming, S. P., Ribeiro, B., \& Aroso, J. (2004).

659 Maturity-associated variation in the growth and functional capacities of

660 youth football (soccer) players 13-15 years. European Journal of Applied

$661 \quad$ Physiology, 91(5), 555-562.

662 Mujika, I., \& Padilla, S. (2001). Physiological and performance characteristics of

663 male professional road cyclists. Sports Medicine, 31(7), 479-487.

664 Myer, G. D., Jayanthi, N., DiFiori, J. P., Faigenbaum, A. D., Kiefer, A. W., Logerstedt, 665 D., et al. (2016). Sports specialization, part II: Alternative solutions to early 666 sport specialization in youth athletes. Sports Health, 8(1), 65-73.

667 Newell, A., \& Rosenbloom, P. S. (1981). Mechanisms of skill acquisition and the 668 law of practice. In J. R. Anderson (Ed.), Cognitive skills and their acquisition 669 (pp. 1-55). Hillsdale: Lawrence Erlbaum Associates.

670 Paton, C. D., \& Hopkins, W. G. (2001). Tests of cycling performance. Sports $671 \quad$ Medicine, 31(7), 489-496.

672 Rivera-Brown, A. M., \& Frontera, W. R. (2012). Principles of exercise physiology:

673 Responses to acute exercise and long-term adaptations to training. $P M \& R$ $674 \quad 4(11), 797-804$.

675 Schneider, W., \& Shiffrin, R. M. (1977). Controlled and automatic human

676 information processing: I. detection, search, and attention. Psychological $677 \quad$ Review, 84(1), 1-66. 
678 Scott, J. P. (1986). Critical periods in organizational process. In F. Falkner and J.M.

679 Tanner (Ed.), Human growth. vol. 1. Developmental biology, prenatal growth.

680 (pp. 181-196.). New York: Plenum Press.

681 Shiffrin, R. M., \& Schneider, W. (1977). Controlled and automatic human

682 information processing: II. perceptual learning, automatic attending, and a

683 general theory

684 Staff, T., Gobet, F., \& Parton, A. (2020). Investigating the period of practice

685 needed to acquire expertise in Great Britain 2012 track and field Olympic

686 athletes.

687 Svetlov, P. G. (1972). Ontogenesis as a purposeful (teleonomic) process. Arkhiv 688 Anatomii, Gistologii i Embriologii, 63(8), 5-16.

689 Tiberiu, P., Mihai, B., Cristian, N., Nicoleta, M. S., Cerasela, D., Martin, D., et al.

690 (2020). Is the strength training a key for performance in cycling? - A case

691 study. 6th International Conference of Universitaria Consortium "FEFSTIM:

692 Physical Education, Sports and Kinesiotherapy-implications in Quality of Life".

693 pp. 31.

694 Tucker, R., \& Collins, M. (2012). What makes champions? A review of the relative

695 contribution of genes and training to sporting success. British Journal of

696 Sports Medicine, 46(8), 555-561.

697 Vaeyens, R., Güllich, A., Warr, C. R., \& Philippaerts, R. (2009). Talent identification

698 and promotion programmes of Olympic athletes. Journal of Sports Sciences,

$699 \quad 27(13), 1367-1380$. 
700 Vazire, S., \& Gosling, S. D. (2004). E-perceptions: Personality impressions based

701 on personal websites. Journal of Personality and Social Psychology, 87(1), $702 \quad 123-132$.

703 Viru, A., Loko, J., Harro, M., Volver, A., Laaneots, L., \& Viru, M. (1999). Critical 704 periods in the development of performance capacity during childhood and 705 adolescence. European Journal of Physical Education, 4(1), 75-119.

706 Ward, P., Hodges, N.J., Williams, A.M. \& Starkes, J. (2007). The road to excellence 707 in soccer: A quasi-longitudinal approach to deliberate practice. High Ability $708 \quad$ Studies, 18, 119-153.

709 Wattbike. (2010). An introduction to the wattbike. Retrieved 07/13, 2013, from 710 http://youtu.be/i6cCcB1jorY

711 Williams, A. M., \& Reilly, T. (2000). Talent identification and development in 712 soccer. Journal of Sports Sciences, 18(9), 657-667.

713 Yustres, I., Santos del Cerro, J., Martín, R., González-Mohíno, F., Logan, O., \& 714 González-Ravé, J. M. (2019). Influence of early specialization in world715 ranked swimmers and general patterns to success. PloS One, 14(6), $716 \quad \mathrm{e} 0218601$. 